\title{
Effect of Mechanochemical Treatment on Magnetic Properties of Nanodimensional Magnetite-Type Materials
}

\author{
Z. Cherkezova-Zheleva ${ }^{a, *}, \mathrm{~K} . \mathrm{Zhharieva}^{a}$, K. Buchkov ${ }^{b}$, B. Blagoev ${ }^{c}$ And I. Mitov ${ }^{a}$ \\ ${ }^{a}$ Institute of Catalysis, Bulgarian Academy of Sciences, "Acad. G. Bonchev" St., Bld. 11, 1113 Sofia, Bulgaria \\ ${ }^{b}$ Institute of Solid State Physics, Bulgarian Academy of Sciences, \\ Tsarigradsko chaussee Blvd., N 72, Sofia 1784, Bulgaria \\ ${ }^{c}$ Institute of Electronics, Bulgarian Academy of Sciences, Tsarigradsko chaussee Blvd., N 72, Sofia 1784, Bulgaria
}

\begin{abstract}
The presented study compares magnetic properties of Ni-doped magnetites $\mathrm{Ni}_{0 .}^{2+} \mathrm{Fe}_{0.5}^{2+} \mathrm{Fe}_{2}^{3+} \mathrm{O}_{4}$ to magnetite $\left(\mathrm{Fe}_{3} \mathrm{O}_{4}\right)$ sample. Physicochemical properties of materials were registered by means of X-ray powder diffraction, Mössbauer spectroscopy, saturation magnetization and physical properties measurement systems. It was obtained that used preparation procedures lead to synthesis of single phase spinel materials with close nanodimensional size about 8-12 $\mathrm{nm}$. Mechanochemically synthesized sample shows better magnetic properties as lower blocking temperature of superparamagnetic state and minimal coercivity in comparison to other studied materials.
\end{abstract}

DOI: $10.12693 /$ APhysPolA.126.912

PACS: 75.60.-d, 75.75.-c, 82.80.Ej

\section{Introduction}

Magnetite and magnetite-type materials are members of solid solution series $\mathrm{Fe}_{3} \mathrm{O}_{4}-\mathrm{Me}_{x} \mathrm{Fe}_{3-x} \mathrm{O}_{4}, \mathrm{Me}=\mathrm{Ni}$, $\mathrm{Co}, \mathrm{Zn}$, etc. Despite of the fact that they are some of the most extensively studied spinels, certain aspects of their electronic and magnetic properties are still not fully understood especially in the case of nanosized materials. The superparamagnetic (SPM) nanoscale composites, with their special properties, have been widely used in many scientific and application areas [1-7]. Recently the main efforts of material science are to alter the magnetic properties of nanodimensional magnetitetype materials by improvement of preparation conditions and by doping them with rare earth or transition metal elements [1-7]. The calculations of magnetic hyperfine fields $\left(B_{\mathrm{hf}}\right)$ at foreign nuclei in the simple ferromagnets (impurities in solids - iron, cobalt, and nickel) were also made. Such investigations lead to a better understanding of the factors influencing the magnetism changes by impurities [5].

Various preparation procedures have been used to produce ferrites, including co-precipitation, hydrothermal, sol-gel methods and mechanical alloying [1-7]. In addition, it has been found that ferrite particles of similar composition differ on their magnetic properties depending on the differences in particle size. Decreasing the particle sizes leads to an increase of non-magnetic species on the particle surface $[2,7]$. The aim of presented paper was to study physicochemical properties of magnetite-type materials by means of X-ray diffraction (XRD), Mössbauer spectroscopy, saturation magnetization and physical properties measurement systems (PPMS). Magnetic properties of nanosized nickel-doped

*corresponding author; e-mail: zzhel@ic.bas.bg magnetite $\mathrm{Ni}_{0.5}^{2+} \mathrm{Fe}_{0.5}^{2+} \mathrm{Fe}_{2}^{3+} \mathrm{O}_{4}$ prepared by different methods were compared to $\mathrm{Fe}_{3} \mathrm{O}_{4}$ sample with approximately the same size.

\section{Experimental}

Magnetite $\mathrm{Fe}_{3} \mathrm{O}_{4}$ and Ni-doped magnetite $\mathrm{Ni}_{0.5}^{2+} \mathrm{Fe}_{0.5}^{2+} \mathrm{Fe}_{2}^{3+} \mathrm{O}_{4}$ were synthesized using $\mathrm{FeCl}_{2} \cdot 4 \mathrm{H}_{2} \mathrm{O}$, $\mathrm{FeCl}_{3} \cdot 6 \mathrm{H}_{2} \mathrm{O}, \mathrm{NiCl}_{2} \cdot 6 \mathrm{H}_{2} \mathrm{O}$, and $\mathrm{NaOH}$. The products were dried at $50{ }^{\circ} \mathrm{C}$ for $3 \mathrm{~h}$. Magnetite was directly synthesized in precipitate, but Ni-doped material contained incompletely reacted intermediates. In this case in order to prepare single phase material two different procedures were used. So the as-prepared sample was: (1) milled in high energy planetary ball mill type PM 100, Retsch, Germany: steel container with volume $250 \mathrm{ml}$; nitrogen atmosphere; $3 \mathrm{~h} ; 500 \mathrm{rpm}$; 30:1 weight ratio between balls and powder; $(2)$ thermally treated at low-temperature in argon media for $3 \mathrm{~h}$ at $300{ }^{\circ} \mathrm{C}$ in the furnace "Eurotherm", England.

Magnetic properties of the produced ferrite materials were studied by the Mössbauer spectroscopy and DC magnetization experiments. Powder X-ray diffraction (XRD) patterns were collected using a TUR-M62 apparatus, Germany using $\mathrm{Co}-\mathrm{K}_{\alpha}$ radiation and JCPDS database. Average crystallite sizes and microstrains were determined from the Williamson-Hall diagram [8]. The Mössbauer spectra at room temperature (RT) and liquid nitrogen temperature (LNT) were recorded with apparatus Wissenschaftliche Elektronik GmbH (Germany), working with a constant acceleration mode and using a ${ }^{57} \mathrm{Co} / \mathrm{Rh}$ (activity $\approx 50 \mathrm{mCi}$ ) source and $\alpha$-Fe standard. The experimentally obtained spectra were subjected to mathematical processing according to the least squares method. The parameters of hyperfine interaction such as isomer shift (IS), quadrupole splitting (QS) and magnetic hyperfine field $\left(H_{\mathrm{hf}}\right)$ as well as the line widths (FWHM) and the relative spectral area $(\mathrm{G})$ of the partial components of the spectra were determined. 


\section{Results and discussion}

The X-ray diffraction analysis of studied samples shows that all materials are non-stoichiometric single phase spinels (Fig. 1). No additional phases are registered. It was established the presence of spinel phase $\mathrm{Fe}_{3} \mathrm{O}_{4}$ (PDF-19-0629) in Fig. 1a and $\mathrm{Ni}_{0.5} \mathrm{Fe}_{2.5} \mathrm{O}_{4}$ (PDF-100325; PDF-75-0449) in Fig. 1b and c. Registered broad and low-intensity diffraction peaks confirm the high dispersion of prepared spinels. The materials are members of solid solution series $\mathrm{Fe}_{3} \mathrm{O}_{4}-\mathrm{NiFe}_{2} \mathrm{O}_{4}$. Their unit cell parameters were calculated from $\mathrm{a}=8.39 \AA\left(\mathrm{Fe}_{3} \mathrm{O}_{4}\right)$ to $\mathrm{a}=8.35-8.36 \AA\left(\mathrm{Ni}_{0.5} \mathrm{Fe}_{2.5} \mathrm{O}_{4}\right)$. According to the Williamson-Hall diagram the mean crystallite size can be estimated as about $8-12 \mathrm{~nm}$ (Table). The XRD patterns and the calculated values show that in the case of the same chemical composition mechanochemically synthesized (MCS) sample $\mathrm{Ni}_{0.5} \mathrm{Fe}_{2.5} \mathrm{O}_{4}$ has a smaller crystallite size than the thermally synthesized (TS) one. In case of X-ray diffraction peaks with low intensities and relatively broad background the second method should be used in order to register the possible presence of amorphous phases, too.

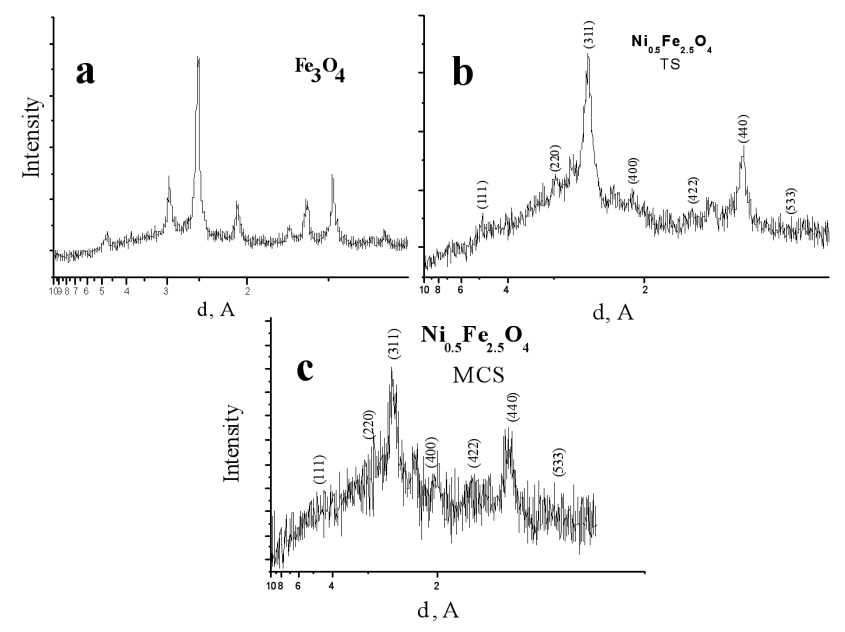

Fig. 1. XRD patterns of: (a) $\mathrm{Fe}_{3} \mathrm{O}_{4}$; (b) $\mathrm{Ni}_{0.5} \mathrm{Fe}_{2.5} \mathrm{O}_{4}$ - thermally synthesized, (c) $\mathrm{Ni}_{0.5} \mathrm{Fe}_{2.5} \mathrm{O}_{4}$ mechanochemically synthesized.

TABLE

Characteristic parameters of the investigated samples: average particle size $(\mathrm{nm}), T_{\mathrm{irr}}[\mathrm{K}], T_{\mathrm{B}}[\mathrm{K}]$ and $\mathrm{H}_{\mathrm{c}}[\mathrm{Oe}]$ values for the investigated samples

\begin{tabular}{c|c|c|c|c}
\hline \hline Sample $\backslash$ properties & $\begin{array}{c}\text { Average } \\
\text { crystallite } \\
\text { size [nm] }\end{array}$ & $\begin{array}{c}T_{\text {irr }}[\mathrm{K}] \\
\text { ZFC-FC } \\
\text { splitting }\end{array}$ & $\begin{array}{c}T_{\mathrm{B}} \\
T_{\text {ZFCmax }} \\
{[\mathrm{K}]}\end{array}$ & $\begin{array}{c}H_{\mathrm{c}} \\
{[\mathrm{Oe}]}\end{array}$ \\
\hline $\mathrm{Fe}_{3} \mathrm{O}_{4}$ (co-prec.) & 12 & 262 & 135 & 18 \\
$\mathrm{Ni}_{0.5} \mathrm{Fe}_{2.5} \mathrm{O}_{4}$ (TS) & 11 & 245 & 232 & 20 \\
$\mathrm{Ni}_{0.5} \mathrm{Fe}_{2.5} \mathrm{O}_{4}$ (MCS) & 8 & $260-280$ & 92 & 12
\end{tabular}

The Mössbauer spectra (MS) of materials at room temperature (RT) and liquid nitrogen temperature (LNT) are recorded. They are shown in Fig. 2. Spectra evaluation was done as an optimal fit of component superposition. It can be seen that RT Mössbauer spectra of magnetite $\mathrm{Fe}_{3} \mathrm{O}_{4}$ sample and thermally prepared Ni-Fe material (Fig. 2a,b) registered the presence of sextet and doublet components. In order to investigate the origin of doublet lines in both cases their LNT Mössbauer spectra are obtained and the RT spectra are completely resolved (Fig. 2a,b). The evaluation of spectra reveals the existence of spinel phase presented by sextet components only. They correspond to tetrahedrally and octahedrally coordinated iron ions in nanosized ferrite materials, having characteristic hyperfine parameters of $\mathrm{Fe}_{3} \mathrm{O}_{4}$ and $\mathrm{Ni}_{0.5} \mathrm{Fe}_{2.5} \mathrm{O}_{4}[2,3,9]$. The calculated values of hyperfine parameters of the three sextet components (Fig. 2a, LNT spectrum) are $\mathrm{IS}_{1}=0.43 \mathrm{~mm} / \mathrm{s}, \mathrm{IS}_{2}=0.34 \mathrm{~mm} / \mathrm{s}$ and $\mathrm{IS}_{3}=0.79 \mathrm{~mm} / \mathrm{s}, \mathrm{QS}_{1}=0 \mathrm{~mm} / \mathrm{s}, \mathrm{QS}_{2}=-0.02 \mathrm{~mm} / \mathrm{s}$ and $\mathrm{QS}_{3}=-0.25 \mathrm{~mm} / \mathrm{s}$. This leads to conclusion of magnetite particles formation having characteristic subspectra of tetrahedrally coordinated $\mathrm{Fe}^{3+}$ and two octahedrally coordinated $\mathrm{Fe}^{3+}$ and $\mathrm{Fe}^{2+}$ ions. The calculated values of hyperfine fields are smaller than the characteristic ones for the bulk material: $\mathrm{H}_{\text {eff1 }}=50.5 \mathrm{~T}$, $\mathrm{H}_{\text {eff2 }}=49.3 \mathrm{~T}$ and $\mathrm{H}_{\text {eff3 }}=46.7 \mathrm{~T}$, which can be explained by smaller crystallite size $[2,3,9]$. In the case of mechanochemically prepared sample the Mössbauer spectrum at RT includes only doublet components (Fig. 2c). The analysis of RT Mössbauer spectra of all studied samples show that the registered doublet components belong to ferrite spinel phase with so-called superparamagnetic (SPM) behavior due to thermally activated reversals of the particles magnetization moments $[2,3,9,10]$. The resulting effect is the absence of magnetic hyperfine structure in the Mössbauer spectra. In this case the core-shell model [10] can be applied to evaluate doublet spectrum resolving two signals in registered quadrupole doublet. They belong to iron ions from the "core" and the interface ("shell layers") of the nanoparticles. The doublet with lowest $\mathrm{QS}=0.66-0.69 \mathrm{~mm} / \mathrm{s}$ belongs to iron ions from the "core" of the particles. The doublet with larger $\mathrm{QS}=1.13-1.25 \mathrm{~mm} / \mathrm{s}$ can be assigned to interface (from the "shell" layers) ferric ions. The lower symmetry in the environment of the "surface" iron ions results in a change in the electric field gradient and therefore in a shift of the QS.

According to the literature data the mean size of oxide particles in MCS sample is about $3-5 \mathrm{~nm}[9,10]$. This result is confirmed by LNT spectrum of material (Fig. 2-c), which is not completely resolved [9, 10]. In this spectrum the SPM doublet component with about $25 \%$ relative weight is registered beside of the sextet components with lower $H_{\text {eff }}$ values, having the characteristic hyperfine parameters of a tetrahedrally coordinated $\mathrm{Fe}^{3+}$ and two octahedrally coordinated $\mathrm{Fe}^{3+}$ and $\mathrm{Fe}^{2+}$ ions. LNT spectrum of the MCS sample is a case of not completely resolved spectrum when the temperature is close, but not lower than so-called blocking temperature where magnetically split subspectra will be registered. 


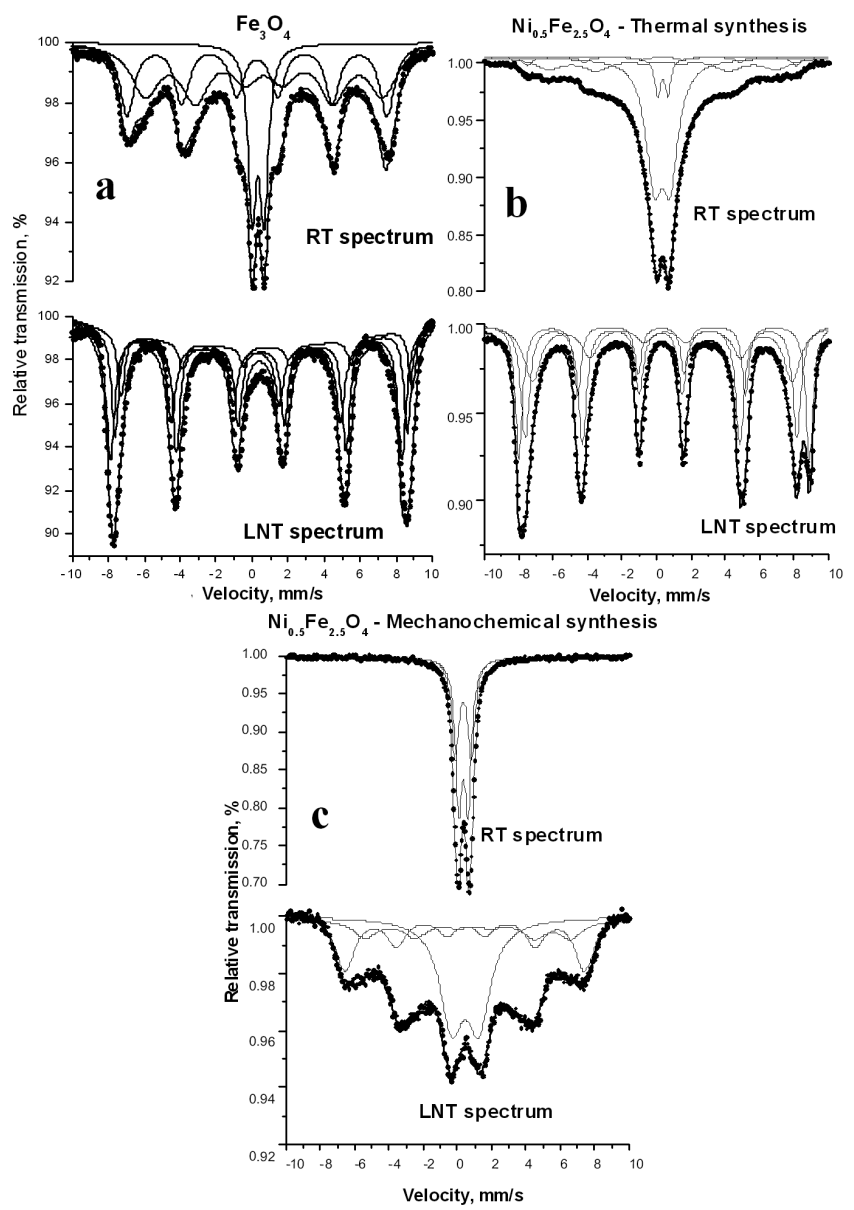

Fig. 2. Mössbauer spectra at RT and LNT of: (a) $\mathrm{Fe}_{3} \mathrm{O}_{4}$, (b) $\mathrm{Ni}_{0.5} \mathrm{Fe}_{2.5} \mathrm{O}_{4}$ - thermally synthesized, (c) $\mathrm{Ni}_{0.5} \mathrm{Fe}_{2.5} \mathrm{O}_{4}$ - mechanochemically synthesized.

The ZFC-FC curves are shown in Fig. 3. There are distinct magnetic moment differences - highest value for $\mathrm{Fe}_{3} \mathrm{O}_{4}$ and about one order of magnitude smaller for the both types of $\mathrm{Ni}_{0.5} \mathrm{Fe}_{2.5} \mathrm{O}_{4}$ nanoparticles, which indicates the successful partial replacement of $\mathrm{Fe}^{2+}\left(4 \mu_{\mathrm{B}}\right)$ by $\mathrm{Ni}^{2+}\left(2 \mu_{\mathrm{B}}\right)$ at the octahedral positions in the spinel structure $[1,11]$.

The ZFC-FC experiments show the typical transition from the blocked (ferrimagnetic state) to the SPM state dominated by thermal fluctuations of magnetic moments. The characteristic transition temperatures $T_{\text {blocking }}\left(T_{\mathrm{B}}\right)$ and $T_{\text {irreversible }}\left(T_{\text {irr }}\right)$ are systematized in Table. The significant $\mathrm{T}_{\mathrm{B}}$ difference for $\mathrm{Ni}_{0.5} \mathrm{Fe}_{2.5} \mathrm{O}_{4}$ (MCS) and $\mathrm{Ni}_{0.5} \mathrm{Fe}_{2.5} \mathrm{O}_{4}$ (TS) (with identical particle size), could be related to possible inter-particle interactions [12] - dependent on the degree of nanoparticles agglomeration, which are different for TS and MCS preparation procedures. There is a considerable $\mathrm{T}_{\mathrm{B}}$ difference comparing $\mathrm{Ni}_{0.5} \mathrm{Fe}_{2.5} \mathrm{O}_{4}$ (MCS) and $\mathrm{Fe}_{3} \mathrm{O}_{4}$, despite the identical average particle size. This could be explained with a decrease of the magneto-crystalline anisotropy energy for $\mathrm{Ni}_{0.5} \mathrm{Fe}_{2.5} \mathrm{O}_{4}$ (MCS), a common feature for all Ni-doped nanoparticles $[1,3,12,13]$. We cannot exclude again the influence of the agglomeration effects typical for wet synthesis methods as co-precipitation [11].

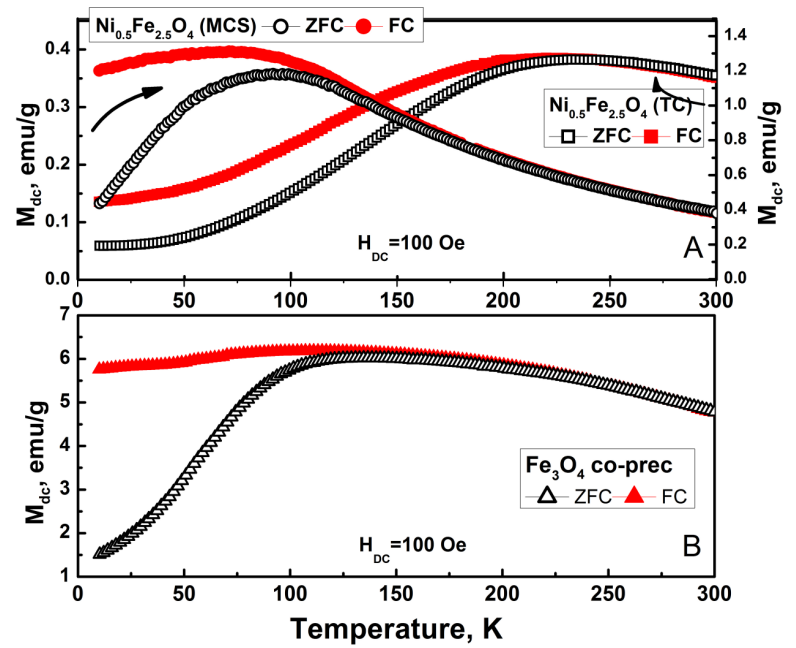

Fig. 3. ZFC-FC magnetization dependence at applied $H_{\mathrm{DC}}=100$ Oe for samples $\mathrm{Ni}_{0.5} \mathrm{Fe}_{2.5} \mathrm{O}_{4}$ (MCS) and $\mathrm{Ni}_{0.5} \mathrm{Fe}_{2.5} \mathrm{O}_{4}$ (TS) (inset A) and for sample $\mathrm{Fe}_{3} \mathrm{O}_{4}$ (inset $\mathrm{B})$.

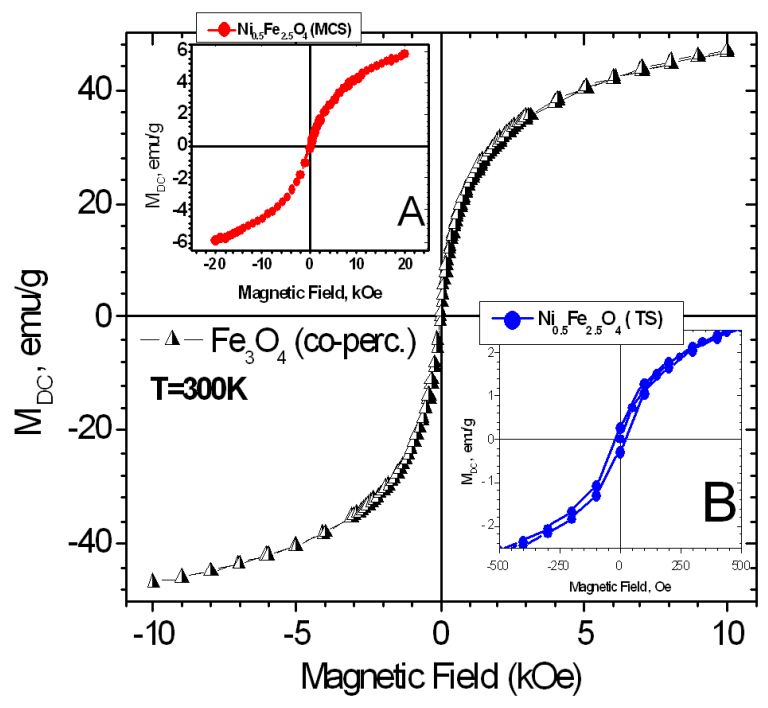

Fig. 4. $M(H)$ hysteresis at $300 \mathrm{~K}$ for $\mathrm{Fe}_{3} \mathrm{O}_{4}$, $\mathrm{Ni}_{0.5} \mathrm{Fe}_{2.5} \mathrm{O}_{4}$ (MCS) (inset A) and for sample $\mathrm{Ni}_{0.5} \mathrm{Fe}_{2.5} \mathrm{O}_{4}$ (TC) (inset B).

In Fig. 4 there are presented the magnetic hysteresis measurements at $300 \mathrm{~K}$, showing very narrow hysteresis for all samples. The imperceptible coercivity $\left(H_{\mathrm{c}}\right)$ of about 10-20 Oe could be due to a non-stoichiometric nanoparticle shells. The minimal $H_{\mathrm{c}}$ value $(\approx 12 \mathrm{Oe}$, see Table) is observed for $\mathrm{Ni}_{0.5} \mathrm{Fe}_{2.5} \mathrm{O}_{4}$ (MCS). Sample $\mathrm{Fe}_{3} \mathrm{O}_{4}$ shows higher $H_{\mathrm{c}}$ value $(\approx 18 \mathrm{Oe})$. This behavior follows the tendencies from the ZFC-FC curves, implying again the differences in the magneto-crystalline anisotropy. The highest $H_{\mathrm{c}}$ value $(\approx 20 \mathrm{Oe})$ is observed for sample $\mathrm{Ni}_{0.5} \mathrm{Fe}_{2.5} \mathrm{O}_{4}$ (TS) with strong implication of hysteresis behavior. This could also be connected with 
the fact that with the strong inter-particle interactions (due to the agglomeration) the material behavior partially transforms from SPM to single domain state $[1,11]$.

\section{Conclusions}

Study of magnetic properties of nanosized $\mathrm{Fe}_{3} \mathrm{O}_{4}$ and $\mathrm{Ni}_{0.5} \mathrm{Fe}_{2.5} \mathrm{O}_{4}$ materials shows superparamagnetic behavior of all ferrite-type materials at room temperature. Mechanochemical synthesis provides the possibility to prepare nanosized materials with enhanced magnetic properties in comparison with thermally treated one. The magnetic behavior (investigated by the ZFC-FC and $\mathrm{M}(\mathrm{H})$ dependences) of the doped samples shows very typical features for the Ni-substituted magnetite nanoparticles: reduced maximal magnetic moment and especially a decrease of the magneto-crystalline anisotropy energy. Additionally, the sample $\mathrm{Ni}_{0.5} \mathrm{Fe}_{2.5} \mathrm{O}_{4}$ prepared by MCS shows the lowest blocking temperature and coercive field, confirming that this approach provides an opportunity for fine adjustment of the magnetic characteristics of the nanoparticles.

\section{Acknowledgments}

The financial support by the European Social Fund within the framework of Operating Program "Development of Human Resources" (BG051PO001-3.3.050001) for covering the expenses for participation in INCOME'2014, Kraków is gratefully acknowledged. The authors are also grateful for the financial support of National Science Fund of Bulgaria under Project DFNIE01/7/2012 for preparation of the paper.

\section{References}

[1] K. Maaz, S. Karim, A. Mumtaz, S.K. Hasanain, J. Liu, J.L. Duan, J. Magn. Magn. Mater. 321, 1838 (2009).

[2] G.A. Sawatzky, F. Van Der Woude, A.H. Morrish, Phys. Rev. 187, 747 (1969).

[3] M.F.F. Lelis, J.D. Fabris, W.N. Mussel, A.Y. Takeuchi, Mater. Res. 6, 145 (2003).

[4] J. Ma, Y. Ji, M. Tian, Mater. Sci.-Poland 27, 981 (2009).

[5] H. Haas, Hyperfine Interact. 151-152, 173 (2003).

[6] E. Sousa, C. Alves, R. Aquino, M. Sousa, G. Goya, H. Rechenberg, F. Tourinho, J. Depeyrot, J. Magn. Magn. Mater. 289, 118 (2005).

[7] K. Haneda, A. Morrish, J. Appl. Phys. 63, 4258 (1988).

[8] G.K. Williamson, W.H. Hall, Acta Metall. 1, 22 (1953).

[9] F. Bødkert, S. Mørup, C. Oxborrow, S. Linderoth, M. Madsen, J. Niemansverdriet, J. Phys. Condens. Matter 4, 6555 (1992).

[10] A. Van Der Kraan, Phys. Status Solidi A 18, 215 (1973).

[11] S. Larumbe, C. Gómez-Polo, J.I. Pérez-Landazábal, A. García-Prieto, J. Alonso, M.L. Fdez-Gubieda, D. Cordero, J. Gómez, J. Nanosci. Nanotechnol. 12, 2652 (2012).

[12] U. Jeong, X. Teng, Y. Wang, H. Yang, Y. Xia, Adv. Mater. 19, 33 (2007).

[13] A.G. Kolhatkar, A.C. Jamison, D. Litvinov, R.C. Willson, T.R. Lee, Int. J. Mol. Sci. 14, 15977 (2013). 